\title{
Coding Subtest (WISC-V)
}

National Cancer Institute

\section{Source}

National Cancer Institute. Coding Subtest (WISC-V). NCI Thesaurus. Code C120360.

A subtest of the Wechsler Intelligence Scale for Children, Fifth Edition. Using a paper key, the subject copies symbols that are paired with numbers within a specified time limit. 